\title{
LA NO RENOVACIÓN DE CONTRATO A LOS PROFESORES DE RELIGIÓN EN LAS ESCUELAS PÚBLICAS POR FALTA DE IDONEIDAD CANÓNICA (AUTONOMÍA DE LAS IGLESIAS Y ACONFESIONALIDAD DEL ESTADO VS. DERECHOS FUNDAMENTALES DEL TRABAJADOR). COMENTARIO A LAS SSTC 38/2007 Y 128/2007
}

JOAQUÍN BRAGE CAMAZANO

Universidad Complutense de Madrid

SUMARIO

I. Introducción.

II. El problema en abstracto: la cuestión de constitucionalidad resuelta por la STC 38/2007.

III. La proyección del problema en un primer caso concreto: el recurso de amparo resuelto por la STC $128 / 2007$.

IV. Reflexión final.

\section{INTRODUCCIÓN}

La religión y la libertad religiosa de los padres tiene un vínculo muy estrecho con la educación, pues esta es un proceso fundamental a través del cual se encauza parte cada vez más considerable del "desarrollo de la personalidad" de los discentes, especialmente en las etapas más tempranas, lo que explica que nuestra Constitución reconozca en su artículo 27,3 a los padres el derecho fundamental a que "sus hijos reciban la formación religiosa y moral que esté de acuerdo con sus propias convicciones", derecho que el Estado debe garantizar; y en cumplimiento de lo anterior, el Acuerdo con la 
Santa Sede en materia de Enseñanza, de 3 de enero de 1979, estipula, respecto de los católicos (pero hay disposiciones análogas en los acuerdos con las comunidades islámica, judía y protestante), que los planes educativos incluirán la enseñanza de la religión católica en todos los centros de educación en condiciones equiparables a las demás disciplinas fundamentales (art. II; otras leyes hacen lo propio respecto de otras Confesiones). ${ }^{1}$ Aquí, sin embargo, no vamos a ocuparnos de la asignatura de religión (católica, en particular) como asignatura en los planes de estudio y su estatus jurídico, sino de la situación jurídica de los profesores encargados de impartirla en los centros públicos.

Hace ya tiempo que es bien conocida entre nosotros, bien que más por la gran resonancia de casos particulares aislados en los medios que por su importancia cuantitativa (en términos absolutos o relativos), la problemática planteada por el "despido" (en realidad, al menos formalmente, "no renovación contractual") de profesores de religión en colegios públicos a raíz de la falta de propuesta por el Obispo correspondiente de un candidato que venía siendo incluido en la relación de propuestos de dicho Obispado en años anteriores pero al que por el Obispo no se le "renueva" la confianza en un momento dado. Esto tiene una incidencia inmediata en la situación laboral del afectado por cuanto que, si bien la relación contractual de los profesores de religión en las Escuelas públicas no está, en la actualidad, ya establecida con la Iglesia (como antes) ni los Obispados, desde un punto de vista legal su nombramiento requiere la declaración canónica de idoneidad por parte del Obispo diocesano correspondiente para cada Curso.

Así se deriva del artículo III del Acuerdo entre el Estado español y la Santa Sede sobre enseñanza y asuntos culturales, de 3 de enero de 1979, ratificado por Instrumento de 4 de diciembre de 1979 (en lo sucesivo, "el Acuerdo"): este precepto establece que, en los niveles educativos de educación preescolar, de educación general básica (EGB) y de bachillerato unificado polivalente (BUP) y en los grados de formación profesional correspondientes a los alumnos de las mismas edades, "la enseñanza religiosa será impartida por las personas que, para cada año escolar, sean designadas por la autoridad académica entre aquéllas que el Ordinario diocesano proponga para ejercer esta enseñanza. Con antelación suficiente, el Ordinario diocesano comunicará los nombres de los Profesores y personas que sean consideradas competentes para dicha enseñanza». La Conferencia Episcopal Española creó, además, la figura de la habilitación episcopal para la docencia como profesores de religión, recogida hoy en la cláusula cuarta del Convenio entre el Estado español y dicha Conferencia, aprobado por Orden de 9 de abril de 1999, habilitación relativa a los urequisitos de formación teológica y pedagogía reli-

1 Con carácter general para todas las confesiones, incluida la católica, cfr. art. 2,1, c) y 2,3 de la Ley Orgánica 7/1980, de 5 de julio, de Libertad Religiosa y Disposición Adicional Segunda de la Ley Orgánica 2/2006, de 3 de mayo, de Educación; y respecto de las Comunidades protestante, islámica y judía, véase el artículo 10 de las Leyes 24, 25 y 26/1992. 
giosa" necesarios para ejercer como profesor de religión en determinados niveles.

Y ahí subyace el problema que abordaremos en este trabajo, por la colisión que ello entraña con los derechos, también fundamentales, del trabajador afectado por la "no renovación" (a partir del R.D. 696/2007, será ya una "revocación" en toda regla), si bien es conveniente comenzar poniendo de relieve que, como antes ya adelantábamos, en términos exclusivamente cuantitativos, la incidencia práctica real de esta facultad eclesiástica de denegar sobrevenidamente la idoneidad a un profesor de religión ya ejerciente es bastante reducida. En concreto, según datos de la Conferencia Episcopal Española, a fecha de 8-12-2006, el número de profesores "que los obispos han dejado de proponer en los últimos 15 años no pasan de uno cada dos años (cifra cotejada con el Ministerio de Educación)".

Lógicamente, la primera cuestión que aquí se plantea, desde la perspectiva del Derecho del Estado español (y dejando a un lado el Derecho canónico), y que se proyecta sobre la aplicación del Derecho ordinario laboral y administrativo, es el de si la normativa legal y del Concordato que da cobertura a esa decisión es conforme a la Constitución, y en particular, si el peso que se otorga a la Iglesia católica en este campo es compatible con los derechos fundamentales del trabajador del que se prescinde y al que, no se olvide, paga su sueldo el Estado; y en todo caso, el juego que han de tener tales derechos en la interpretación y aplicación de esta normativa.

Este es el problema de fondo que aquí surge y con el que se han enfrentado numerosos tribunales en la aplicación de la legalidad ordinaria. Las soluciones que la jurisdicción ordinaria ha ido dando al problema son variadas. ${ }^{2}$ Ahora, a través de las SSTC 38 y 128/07, nuestro Tribunal Constitucional se ha visto enfrentado a la problemática aquí expuesta desde el punto de vista de la constitucionalidad, y en particular de los derechos fundamentales. Si en la primera de las sentencias comentadas el Tribunal en Pleno aborda la cuestión en una perspectiva normativa/general, dando respuesta a las dudas planteadas por el Tribunal Superior de Justicia de Canarias (Sección 1. ${ }^{a}$ de la Sala de lo Social) a través de la cuestión de inconstitucionalidad núm. 4831-2002, ${ }^{3}$ en la segunda sentencia la Sala $2 .^{a}$ se ve en la situación de proyectar esa doctrina general sentada en la STC 38/07 sobre un caso particular, al resolver un recurso de amparo, si bien aquí sólo haremos alguna referencia a esta última STC $128 / 2007$.

2 Cfr. MORENO BOTELLA, Gloria, "Autonomía de la Iglesia, profesorado de religión y constitucionalidad del Acuerdo sobre Enseñanza de 3 de enero de 1979. A propósito de la STC 38/2007 de 15 de febrero", Iustel. Revista General de Derecho Canónico y Derecho Eclesiástico del Estado, núm. 14, mayo de 2007 (www.iustel.com), pp. 8 y ss.

3 Cfr. también las SSTC 80 a 90/2007, de 19 de abril todas ellas, que resuelven otras tantas cuestiones de inconstitucionalidad planteadas también por el mismo tribunal ordinario. 


\title{
II. RESOLUCIÓN DEL PROBLEMA “EN ABSTRACTO" A TRAVÉS DE LA CUESTIÓN DE CONSTITUCIONALIDAD RESUELTA POR LA STC 38/20074
}

\author{
A) RÉGimen CONCORDATARIO Y LEGAL DE LOS PROFESORES DE RELIGIÓN \\ EN LA ESCUELA PÚBLICA
}

La principal base normativa del régimen de los profesores de religión en la Escuela pública se contiene en el Acuerdo de 1979, que establece los siguientes principios: 1. La enseñanza de la religión en la Escuela (preescolar, educación general básica, bachillerato unificado polivalente) será voluntaria: ni será obligatorio impartirla para ningún profesor, ni recibirla para ningún alumno, siendo un derecho de este y sus padres, pero no una obligación en ningún caso (artículos II y III); 2. "La enseñanza religiosa será impartida por las personas que, para cada año escolar, sean designadas por la autoridad académica entre aquellas que el Ordinario diocesano proponga para ejercer esta enseñanza. Con antelación suficiente, el Ordinario diocesano comunicará los nombres de los Profesores y personas que sean consideradas competentes para dicha enseñanza" (artículo III).

El Tribunal Constitucional en su sentencia se extiende en el desarrollo normativo histórico que ha tenido esta previsión pacticia. Importa aquí destacar que desde el principio se partió, en la regulación normativa, de que la regla general sería que los profesores del Centro encargados de otras materias asumirían, sobre la base siempre del principio de voluntariedad, la docencia

4 Vamos a prescindir aquí de varias cuestiones procesales de interés que se plantean en esta sentencia: a) de un lado, la idoneidad de un tratado constitucional para ser objeto de un control "a posteriori" de la constitucionalidad, con los inconvenientes que ello implica en la esfera internacional a la luz de la Convención de Viena sobre Derecho de los Tratados, afirmando el Tribunal Constitucional su idoneidad, lo que le permite entrar en el fondo de la cuestión; b) la necesidad de acudir, en caso de estimar la inconstitucionalidad, a una sentencia atípica y a cuál en concreto (como podría ser la de "mera inconstitucionalidad"), algo en lo que el Tribunal Constitucional no entra, aunque se refiere a la posibilidad de que la declaración de inconstitucionalidad de un tratado internacional pueda producir consecuencias diversas de las previstas literalmente en la L.O.; y por otro lado, c) aunque el Tribunal Constitucional no lo diga expresamente en la sentencia (ni debía decirlo), parece deducirse de su doctrina que la "densidad de control" constitucional se reduce, en una relación inversamente proporcional con su "prudencia", en los casos en que se enjuicie la constitucionalidad de la Ley Orgánica del Tribunal Constitucional o un Tratado internacional; y, por último, d) una cuestión académica: el Tribunal Constitucional habla reiteradamente de que lleva a cabo un control "abstracto", lo cual es discutible desde la perspectiva de la dogmática de la justicia constitucional, pues es sabido que la cuestión de inconstitucionalidad, tomada del Derecho germánico y totalmente influenciada por este, se denomina en este Derecho precisamente "control normativo concreto" de la constitucionalidad, en contraste con el control a través de nuestro recurso de inconstitucionalidad, que sería un "control normativo abstracto", porque, a diferencia de lo que ocurre en este último caso, en el primero la dialéctica del caso concreto tendría un peso digno de mención y condicionaría el enjuiciamiento (aunque no sus efectos, que es cosa distinta, pues cuando los efectos se limitan al caso concreto, y no son un juicio a la ley on its face, podríamos hablar ya de un control concretísimo de la constitucionalidad). 
religiosa, siempre y cuando contaran con la aprobación del Obispo, y sólo excepcionalmente se acudiría a otras personas que la Iglesia declarase competentes e idóneas y propusiera para ello, pudiendo el Obispo en todo caso proponer igualmente su cese (cláusulas 3,5 y 3,7 de la Orden de 16 de julio de 1980). Sin embargo, la realidad es que lo primero no se ha cumplido nunca y han sido completamente excepcionales los casos de docencia religiosa impartida por funcionarios docentes de otras materias, y la regla general es la prevista normativamente como excepción: acudir a profesores "ad hoc", nombrados y cesados a propuesta del Obispo diocesano correspondiente. En cuanto a la naturaleza jurídica de la relación de dichos profesores con la Administración, baste con indicar aquí que, al menos desde 1998, se reconoce que se trata de una relación "laboral", bien que por tiempo determinado, por curso académico, aunque recientemente se la ha transformado, por Real Decreto, en una relación laboral por tiempo indefinido.

Aunque ello no tiene relevancia para el caso decidido por la STC 38/2007, aquí debemos también hacernos eco de la Ley Orgánica 2/2006, de 3 de mayo, de Educación, que ha venido a consagrar definitivamente el carácter laboral de la relación con la Administración de todos los profesores de religión (que no sean funcionarios docentes). Su Disposición Adicional Tercera, 3, dice: "En todo caso, la propuesta para la docencia corresponderá a las entidades religiosas y se renovará anualmente cada año [...] La remoción se ajustará a Derecho". Y por otro lado, el Real Decreto 696/2007, de 1 de junio, por el que se regula la relación laboral de los profesores de religión, se refiere en su preámbulo a la "relación de confianza y buena fe" de estos profesores con el Obispo; asimismo, establece su carácter indefinido (y ya no temporal, anual para ser más exactos), aunque en su artículo 7 prevé que "el contrato de trabajo se extinguirá: [...] b) Por revocación ajustada a derecho de la acreditación o de la idoneidad para impartir clases de religión por parte de la Confesión religiosa que la otorgóm.

Desde el punto de vista de los derechos fundamentales de la Iglesia como comunidad, el carácter indefinido del contrato de trabajo (que es la "SOlución italiana", por ejemplo) ${ }^{6}$ no plantea problema alguno por cuanto que se sigue garantizando en todo caso el cese a propuesta del Obispo, y aunque ello contribuye a que lo que hasta era, formalmente, una "no renovación" del contrato se vea ya como un "despido" (creemos que, materialmente, ya lo era cuando afectaba a un trabajador con continuidad laboral de años, y así se veía en todo caso en la opinión pública), no cabe duda que lo relevante es que proporciona a estos trabajadores una justa estabilidad jurídica ajustada a la

5 Basta una lectura superficial de la Orden para comprobar que se trata de cláusulas (pactadas con la Conferencia Episcopal, como se reconoce en la propia Orden) y no, como dice el Tribunal Constitucional, de artículos.

6 GONZÁLEZ-VARAS IBÁÑEZ, Alejandro, "El régimen jurídico de los profesores de religión en Italia", Iustel. Revista General de Derecho Canónico y Derecho Eclesiástico del Estado, núm. 14, mayo de 2007 (www.iustel.com), in toto. 
continuidad de facto de muchos de ellos (buena parte de los profesores de religión llevan 15 años o más trabajando como tales, incluso de forma gratuita en sus comienzos), que eran renovados año tras año (era una reivindicación vieja del colectivo, siendo completamente injustificada su denegación). ${ }^{7} \mathrm{Y}$, sea como sea, no plantea problemas en cuanto a la compatibilidad con el Acuerdo de Enseñanza y los derechos de la Iglesia, pues incluso dichos Acuerdos hablan de la propuesta de "cese" (y no propuesta de "no renovación") del Obispo a las autoridades académicas de un profesor al que sobrevenidamente no se considera apropiado, lo que podrá aplicarse para negar la "prórroga automática anual" o incluso para un cese anticipado a la prórroga.

Sin embargo, la Conferencia Episcopal se ha posicionado muy críticamente en torno a otros dos aspectos: a) por un lado, sostiene que "la mera invocación de una "revocación ajustada a Derecho" (art. 7) — sin aclarar a qué Derecho se refiere- puede restringir indebidamente la competencia del Obispo para retirar la idoneidad cuando tenga que hacerlo en virtud de las previsiones del ordenamiento jurídico de la Iglesia (véase el canon 804)»; y b), por otro lado, afirma que "el destino de los profesores a un puesto determinado forma parte de la misión de enseñar religión católica, misión que el Obispo no da en abstracto o de modo genérico, sino teniendo en cuenta las circunstancias concretas de lugar y personas. Ésa ha sido la praxis constante en la interpretación de los Acuerdos, que ha sido corroborada por el Tribunal Supremo (véase la Sentencia de 29 de septiembre de 2004)".

Desde nuestro punto de vista, la primera objeción en realidad sólo expresa un temor a un peligro que difícilmente se verificará nunca en la realidad, especialmente tras la STC 38/2007, que diseña el marco de la "Conformidad a Derecho" de una propuesta de cese a instancias del Obispo, incluyendo la actuación de este conforme al Código Canónico, como no podía ser de otro modo.

En cuanto a la segunda objeción, sí que nos parece completamente suscribible lo que se defiende por la Conferencia Episcopal, pues, aun cuando sea muy discutible la corrección técnico-canónica de la calificación como "missio canonica" de la función de los profesores de religión, ${ }^{8}$ lo que sí nos pare-

\footnotetext{
7 Desde luego, la situación de los profesores de religión no es única y ahora contrasta con la de otros colectivos en los que la renovación anual nos parece que estaría menos justificada todavía en términos objetivos, como los jueces sustitutos y magistrados suplentes (al poder afectar la temporalidad, quiérase o no, a su independencia, que jugaría a favor de una mayor estabilidad).

8 En este sentido, véase OTADUY GUERIN, Jorge, «Idoneidad de los profesores de religión. Una revisión necesaria y urgente. A propósito de la sentencia 38/2007, de 15 de febrero, del Tribunal Constitucional", Iustel. Revista General de Derecho Canónico y Derecho Eclesiástico del Estado, núm. 14, mayo de 2007 (www.iustel.com), p. 7: es un mandato más que una verdadera "missio canonica", que atribuye facultades normalmente vinculadas al ejercicio de la potestad sagrada de la Iglesia. La Conferencia Episcopal, no obstante, parece entender que el profesor participa así en la "potestad de la Iglesia de enseñar su doctrina" (Cuestión núm. 30 de: Secretariado de la Comisión Episcopal de Enseñanza y Catequesis de la Conferencia Episcopal Española, Cincuenta preguntas a la enseñanza de la Religión Católica en la escuela, EDICE/Fundación Santa María, Madrid, 2005, pp. 21-22).
} 
ce claro es que, desde una perspectiva constitucional, la "confianza" del Obispo con relación a un determinado profesor de religión ha de serlo para ocupar un puesto en un Centro o lugar determinados, por lo que el Decreto, en este punto, nos parece que vulnera flagrantemente la libertad religiosa, siendo una intromisión del Estado en un ámbito que sólo corresponde a las Confesiones religiosas y una quiebra inadmisible (y grave) de la neutralidad del Estado, una verdadera "inmissio" en el terreno religioso difícilmente justificable, que afecta también de modo reflejo al derecho de los padres a que sus hijos reciban una formación acorde con sus convicciones religiosas (art. 27,3 $\mathrm{CE})$, y que, además, más allá de lo estrictamente jurídico, crea un problema donde realmente no lo había, lo que no suele ser una política inteligente.

Nos parece, además, que es una burla de lo que el Tribunal Constitucional ha dicho en la STC 38/2007, tratando de restringir el ámbito de la confianza del Obispo sobre los profesores de religión en cuanto a su competencia e idoneidad, a fin de que sea una "confianza en abstracto" sobre una persona y no para que dicha persona ejerza su función en un determinado lugar o Centro (y por tanto, en unas determinadas circunstancias sociales, económicas, políticas, etc), que resulta incuestionable que es un factor que las Confesiones, y en particular la Iglesia Católica (cuya enseñanza es sabido que tiene innumerables adaptaciones locales o casuísticas), pueden considerar, de modo enteramente razonable, de importancia (o simplemente determinante) para valorar a quien proponen, y a quien no, para enseñar la asignatura de religión en un determinado Centro.

Así había sido hasta ahora. Una buena prueba de ello es que, entre los Criterios Generales aprobados por la Conferencia Episcopal Española el 24-111995, hace ya más de una década por tanto, sobre la selección y permanencia de profesores de religión, se halla uno que dice "cuando se trata de elegir para permanecer en el Centro: añadir a los criterios anteriores una evaluación de su integración en el mismo (grado de aceptación por parte de los alumnos y de los demás profesores)»; más recientemente, en 2005, se reiteraba que la propuesta de designación por el Obispo de los profesores lo es "para impartir clases en un colegio determinado y para unos alumnos concretos $"{ }^{9}$ Este es el auto-entendimiento por la propia Iglesia de lo que conllevaba la "autonomía de la Iglesia ${ }^{10}$ en este ámbito, a lo que el Estado ha asentido por décadas en

9 Cfr., la cuestión núm. 30 de: Secretariado de la Comisión Episcopal de Enseñanza y Catequesis de la Conferencia Episcopal Española, Cincuenta preguntas a la enseñanza de la Religión Católica en la escuela, EDICE/Fundación Santa María, Madrid, 2005, p. 21: "Una vez adquirida esta Declaración Eclesiástica de Idoneidad académica, el Ordinario Diocesano es quien debe examinar las titulaciones, cursos, circunstancias religiosas y demás peculiaridades de cada candidato a la docencia que le ayuden a discernir cuál es el profesor, entre aquellos que poseen la idoneidad académica, que debe proponer a la Administración para impartir clases en un colegio determinado y para unos alumnos concretos".

10 Esta autonomía aparece garantizada, además de por el art. I del Acuerdo con la Santa Sede de Asuntos Jurídicos (.libre y público ejercicio de las actividades [...] de [...] Magisterio"), por el art. 6 de la Ley Orgánica 7/1980, de 5 de julio, de Libertad Religiosa: "Las Iglesias, Confesiones 
la praxis, y que ahora el Estado ha derogado unilateralmente en lo que es una quiebra grave de la libertad religiosa comunitaria por cuanto que afecta al contenido nuclear de dicho derecho fundamental en este ámbito mediante una intromisión del Estado en un aspecto que sólo corresponde definir y decidir a las autoridades eclesiásticas y reflejamente además acaba afectando también al derecho fundamental del art. 27,3 CE, pues en último término será el Estado quien asigne a un profesor de religión a un determinado Centro, incluso si la Iglesia, sobre la base de criterios que sólo ella debería valorar, no considera idóneo a ese profesor para ese Centro; y además ello no se hace sino a costa de romper con el principio de neutralidad religiosa del Estado y prescindiendo del derecho del art. 27,3 CE aquí en juego.

\section{B) LA ACONFESIONALIDAD DEL ESTADO VERSUS LA SUPUESTA IRREVISIBILIDAD ESTATAL DE LA DECLARACIÓN CANÓNICA DE IDONEIDAD DE LOS PROFESORES DE RELIGIÓN: EL "ORDEN PÚBLICO CONSTITUCIONAL DE VALORES Y PRINCIPIOS" COMO PARÁMETRO DE REVISIÓN}

El órgano judicial que plantea la cuestión de constitucionalidad al Tribunal Constitucional considera que la contratación de los profesores de religión en los centros escolares públicos por la Administración pública es contraria al principio de aconfesionalidad del Estado del art. 16,3 CE, y ello aun teniendo presente que dicho artículo también establece un deber de cooperación con las confesiones religiosas, y en particular con la Iglesia Católica, a la que cita expresamente.

El Tribunal Constitucional no hace cuestión de la legitimidad de la inserción de la enseñanza de la religión católica en el sistema educativo como asignatura de seguimiento libre, pues nadie suscitó su inconstitucionalidad en el proceso, y en todo caso es un "cauce posible para la realización de la libertad religiosa" de la Iglesia Católica como sujeto colectivo o comunidad, "en concurrencia con el ejercicio del derecho a una educación conforme con las propias convicciones religiosas y morales" de los padres de los alumnos que opten por estudiar esta asignatura.

y Comunidades religiosas inscritas tendrán plena autonomía y podrán establecer sus propias normas de organización, régimen interno y régimen de su personal. En dichas normas, así como en las que regulen las instituciones creadas por aquellas para la realización de sus fines, podrán incluir cláusulas de salvaguarda de su identidad religiosa y carácter propio, así como del debido respeto a sus creencias, sin perjuicio del respeto de los derechos y libertades reconocidos por la Constitución, y en especial de los de libertad, igualdad y no discriminación". Sobre esta dimensión de la libertad religiosa, véase LÓPEZ-SIDRO LÓPEZ, Ángel, "Dimensión colectiva del derecho de libertad religiosa en los centros docentes públicos: la designación de los profesores de religión", Iustel. Revista General de Derecho Canónico y Derecho Eclesiástico del Estado, núm. 14, mayo de 2007, p. 12 (www.iustel.com). 
Tampoco se plantea a fondo la constitucionalidad de que sean las confesiones, y no el Estado, quienes definan el credo religioso objeto de enseñanza, pero afirma que así lo exige el principio de neutralidad del Estado en el ámbito religioso derivado del art. 16,3 CE (SSTC 24/1982, de 13 de mayo; y 340/1993, de 16 de noviembre): "El credo religioso objeto de enseñanza ha de ser, por tanto, el definido por cada Iglesia, comunidad o confesión, no cumpliéndole al Estado otro cometido que el que se corresponda con las obligaciones asumidas en el marco de las relaciones de cooperación a las que se refiere el art. 16,3 CE". Ello también le lleva a la conclusión de que "también ha de corresponder a las confesiones la competencia para el juicio sobre la idoneidad de las personas que hayan de impartir la enseñanza de su respectivo credo", pudiendo referirse ese juicio no sólo "a la estricta consideración de los conocimientos dogmáticos o de las aptitudes pedagógicas" de los docentes, sino también "a los extremos de la propia conducta en la medida en que el testimonio personal constituya para la comunidad religiosa un componente definitorio de su credo, hasta el punto de ser determinante de la aptitud o cualificación para la docencia, entendida en último término, sobre todo, como vía e instrumento para la transmisión de determinados valores. Una transmisión que encuentra en el ejemplo y el testimonio personales un instrumento que las Iglesias pueden legítimamente estimar irrenunciable".

Aclarado lo anterior, el Tribunal Constitucional entra ya propiamente en los motivos de inconstitucionalidad aducidos por el órgano proponente de la cuestión, que consideraba que la relación de los profesores de religión era una "laboral" (Disposición adicional segunda de la L.O. 1/1990 en la redacción dada por la L.O. 50/1998, de 30 de diciembre) y con la Administración, lo que chocaría con el principio de aconfesionalidad del Estado, pues la intervención prevista de la jerarquía eclesiástica para proponer de manera vinculante el nombramiento y el cese a los profesores en atención a criterios de idoneidad de índole religiosa y confesional (art. III del Acuerdo) condicionaría el acceso al empleo público y el mantenimiento en el mismo en base a criterios religiosos y además se generaría una inmunidad frente al Derecho estatal de las decisiones sobre contratación y renovación adoptadas por el Obispado sobre la base de tales criterios y de ordenamiento distinto del estatal (el Derecho canónico).

Pues bien, el Tribunal Constitucional considera, en primer lugar, que la Disposición adicional Segunda de la L.O. 1/1990 se limita a establecer la naturaleza "laboral" de la relación entre los profesores de religión y la Administración educativa, y eso, lejos de dar lugar a una inmunidad de control jurisdiccional, implica la plena competencia del orden jurisdiccional social.

Y en cuanto a la supuesta inmunidad jurisdiccional derivada de la intervención de los Obispos, el Tribunal comienza por "rechazar tajantemente su concurrencia". Lejos de ello, sostiene que, al igual que respecto de todos los actos discrecionales de cualquier autoridad cuando producen efectos en terceros (discrecionalidad técnica, STC 86/2004, de 10 de mayo, FJ 3. ${ }^{\circ}$; nombramientos de libre designación, STC 235/2000, de 5 de octubre), es posible un control de legalidad. Aquí el Tribunal reconoce, en primer lugar, una "libertad 
de criterio" de las confesiones; pero también fija como límite a esa libertad, que no es absoluta, el "orden constitucional de valores y principios" (cláusula del orden público constitucional): podríamos condensar que hay una "deferencia" del Estado hacia las decisiones eclesiásticas, que vendría exigida por el respeto a la libertad religiosa de las Confesiones, el deber de neutralidad estatal en el campo religioso y el derecho de los padres ex art. 27,3 CE, pero que no es una deferencia absoluta, sino sujeta, como cualquier derecho fundamental, a la ponderación con otros derechos fundamentales concurrentes, si bien de la STC 128/2007 se deduce que esa deferencia va a ser de muy largo alcance. Y al concluir que ni la Disposición Adicional Segunda de la L.O. 1/1990 ni el artículo III del Acuerdo de Enseñanza con la Santa Sede (1979) excluyen la competencia de los jueces y tribunales, algo que sería inconstitucional en todo caso, desestima la cuestión de inconstitucionalidad en este punto.

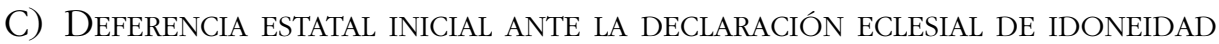 CANÓNICA Y CRITERIOS PRACTICABLES DE REVISIÓN JURISDICCIONAL EN CUANTO A SU COMPATIBILIDAD CON EL ORDEN PÚBLICO CONSTITUCIONAL, EN PARTICULAR LOS DERECHOS FUNDAMENTALES DEL TRABAJADOR AFECTADO}

El Tribunal Constitucional, además, alude, en una serie de "obiter dicta", a que los órganos jurisdiccionales llamados a controlar los casos de no renovación contractual de profesores de religión a instancias de la autoridad eclesiástica, y en último término el propio Tribunal Constitucional, "deben ponderar los diversos derechos fundamentales en juego", es decir, "encontrar criterios practicables que permitan conciliar en el caso concreto las exigencias de la libertad religiosa (individual y colectiva) y el principio de neutralidad religiosa del Estado con la protección jurisdiccional de los derechos fundamentales y laborales de los profesores". Y en otro "obiter dictum" apunta el Tribunal Constitucional a algunos de estos "criterios practicables":

a) Debe controlarse "si la decisión administrativa se ha adoptado con sujeción a las previsiones legales": si la designación se ha realizado entre las personas que el Diocesano ordinario ha propuesto para ejercer esta enseñanza y, dentro de las personas propuestas, en condiciones de igualdad y con respeto a los principios de mérito y capacidad; o si la falta de designación de una persona se debe a que no se le propone por el Obispo. Aquí el Tribunal Constitucional, como tantas veces, sienta su doctrina sin hacerse eco siquiera de la realidad de las cosas, que es de suponer que no se desconoce, en el sentido de que, pese a la dicción del Acuerdo de enseñanza de 1979, en la práctica, año tras año, el número de profesores propuesto coincide con el de plazas a cubrir, con lo cual el ámbito de decisión por la Administración, en una práctica admitida de modo generalizado, se reduce a cero. 
b) También debe ser objeto de control «si la falta de propuesta por parte del Ordinario del lugar responde a criterios de índole religiosa o moral, que determinarían la inidoneidad de tal persona para la enseñanza religiosa, o bien responde a otros criterios. En el primer caso, corresponde a las autoridades religiosas definir tales criterios religiosos o morales determinantes de la no propuesta por el Obispo de una persona, pues así lo exige la libertad religiosa y el principio de neutralidad religiosa del Estado ${ }^{11}$.

c) Deben ponderarse los eventuales derechos fundamentales en conflicto a fin de determinar "cuál sea la modulación que el derecho de libertad religiosa que se ejerce a través de la enseñanza de la religión en los centros escolares pueda ocasionar en los propios derechos fundamentales de los trabajadores en su relación de trabajo". Aquí debería operar siempre el principio de "concordancia práctica", ideado por Konrad Hesse, asumido por el Tribunal Constitucional alemán y que ha pasado también, en cierta medida y de forma un tanto retórica en ocasiones, a nuestra jurisprudencia constitucional. Habría que tener siempre presente que, en los casos más típicos de conflicto, en uno de los polos habría concurrencia ideal (y no de leyes o pseudoconcurrencia) ${ }^{12}$ de varios derechos

11 Cfr. el canon 804 del Código de Derecho Canónico: "Cuide el Ordinario del lugar de que los profesores que se destinan a la enseñanza de la religión en las escuelas, incluso en las no católicas, destaquen por su recta doctrina, por el testimonio de su vida cristiana y por su aptitud pedagógica"; y el canon 805 le autoriza a nombrar o aprobar los profesores de religión, así como removerlos o exigir su remoción "cuando así lo requiera una razón de religión o moral". Aquí deberíamos hacernos eco de que la Iglesia española carece de una normativa "local" sobre los criterios que han de determinar la idoneidad y competencia de los profesores de religión (que parece hacerse más necesaria todavía en la actualidad, al no ser ya el contrato laboral de los profesores de religión anual, sino indefinido), pero al menos sí hay ciertos documentos de la Conferencia Episcopal que ayudan a definir esos criterios, que más bien parecen ser simples arecomendaciones generales": Cfr. el más reciente documento, "Principios y criterios para la inspección del área y el seguimiento de los profesores de religión católica", aprobado el 24-IV-2001 en la LXXVI Asamblea Plenaria de la Conferencia Episcopal Española, de 27 de abril de 2001, punto 7; y los "Criterios generales" aprobados, a propuesta de la Comisión Episcopal de Enseñanza y Catequesis, por la Asamblea Plenaria de la Conferencia Episcopal Española el 24-11-1995 (Criterios Generales "que eviten agravios comparativos y que faciliten la elección de los profesores más idóneos, no sólo como profesionales de la enseñanza sino como evangelizadores enviados por el obispo en nombre de la Iglesia"), Boletín Oficial de la Conferencia Episcopal Española, núm. 49, 1996, pp. 61-62. Estos Criterios incluyen, junto a unos indudablemente "religiosos" (condición de católico practicante; formación permanente y actualización; compromiso eclesial), otros llamados "circunstanciales (para casos de igualdad de condiciones): a. Antigüedad; b. Cercanía al Centro; c. Precariedad económica; d. Necesidades familiares". En esta última hipótesis, por ejemplo, es claro que no estamos ante criterios realmente religiosos, por lo que entendemos que decaería la "deferencia" del control jurisdiccional motivada por el respeto de la libertad religiosa y deber estatal de neutralidad y derecho del art. 27,3 CE.

12 Sobre estas categorías de teoría general de los derechos fundamentales y sus límites, que son completamente diversas del conflicto de derechos fundamentales (no presuponen dos o más titulares de derechos fundamentales, sino sólo uno) y que hemos propuesto adoptar en España a partir del Derecho alemán, véase BRAGE CAMAZANO, Joaquín, Los limites a los derechos fundamentales, Dykinson, Madrid, 2004, pp. 185 y ss. y 409 y ss. 
fundamentales (libertad religiosa comunitaria o colectiva de la Confesión de que se trate, libertad religiosa individual de los padres y de los menores, derecho también individual de los padres a que sus hijos reciban una formación religiosa y moral conforme a sus convicciones y no a las del Estado o un individuo determinado disidente de la Confesión), que se verían afectados casi siempre en su ámbito nuclear si el Estado «niega efecto" a la propuesta de nombramiento o cese del Obispo; y en el otro polo, podría estar el derecho a la intimidad de los profesores, que se verá tanto menos afectado en su núcleo en cuanto que la propuesta de cese del Obispo se base en motivos que son públicos o que el afectado ha hecho públicos incluso, aunque en este último caso puede entrar en juego la libertad de expresión ${ }^{13}$ en concurrencia con el derecho fundamental a la intimidad. La concordancia práctica exige que ni los derechos fundamentales "de religión" cedan ante la intimidad y libertad de expresión ni tampoco a la inversa, lo que exigirá una ponderación casuística, que permitirá ir formulando reglas y principios (por ejemplo, creemos que, aunque aquí no podemos detenernos en su justificación, pueden formularse principios como estos: «cuanto más afecte la propuesta eclesiástica de cese a la intimidad, a aspectos no públicos ni generalmente conocidos del trabajador, más difícil será de justificar esa "cesión" del derecho a la intimidad frente a la libertad religiosa, etc.»; o que "la concurrencia junto a la intimidad de la libertad de expresión o información refuerza la posición del trabajador, aunque generalmente su intimidad se verá, a su vez, debilitada por propia decisión del afectado"; o que "cuanto más ligada esté la propuesta de cese a normas religiosas estimadas fundamentales por la Confesión, ${ }^{14}$ y aun siendo la conducta infractora de las mismas por el afectado algo lícito o incluso un derecho en el ámbito estatal, mayor tiene que ser la afectación de los derechos fundamentales del trabajador para que pueda dejarse sin efecto la propuesta eclesial", etc) y podría llevar incluso a exigir regulaciones complementarias de compensación, como comentarios al final del artículo.

Desde nuestro punto de vista, y al margen de lo anterior, la revisión jurisdiccional en los casos de "cese" o "no renovación" de un profesor de religión a instancias del Obispo de la diócesis que corresponda permite un "control por capas". Así, sin ánimo exhaustivo:

13 Cfr. STC 80/2007, de 19 de abril, que analiza otra cuestión de constitucionalidad planteada respecto del artículo III del Acuerdo de Enseñanza desde la perspectiva de la libertad de expresión, desechando su incompatibilidad de plano, por no aportarse razones que lo avalen, «sin perjuicio de las consideraciones que, en su caso, proceda efectuar en el ámbito del control concreto de los actos de aplicación de estas disposiciones legales y de su conformidad con los derechos fundamentales" (FJ 2. ${ }^{\circ}$ ).

14 Cfr. SSTEDH de 14-12-1999, caso "Serif c. Grecia"; y 26-5-2000, caso "Hasan y Chaush c. Bulgaria" (prohibición general de interferencia estatal en cuestiones religiosas de las confesiones aunque generen cierta tensión social). 
- Una primera capa, relativa a los motivos por los que el Ordinario deniega su propuesta a quien se había propuesto en otras ocasiones por considerar que ha devenido inidóneo: aquí el control de los órganos jurisdiccionales del Estado, en virtud del delicado principio que prohíbe al Estado valorar las creencias de sus ciudadanos, se habría de limitar al control de arbitrariedad (por ejemplo: han de constar motivos para la decisión episcopal y han de ser de tipo religioso o moral ${ }^{15}$; y no puede ser palmario que tales motivos no concurren en el caso concreto de que se trate; como el afectado puede recurrir la decisión episcopal como acto administrativo, debe valorarse si efectivamente tuvo esa posibilidad de recurso en el ámbito canónico, si hizo uso o no de ella y los motivos expresados por el tribunal eclesiástico al que recurriera). Por ejemplo, si un Obispo deja de proponer un año a un determinado profesor por no ser este ya católico, ${ }^{16}$ los tribunales estatales no podrán revisar esa exigencia de catolicidad en sí misma más que superfluamente, a fin de garantizar que no sea arbitraria o no tenga nada que ver, de manera patente, con la idoneidad para la docencia religiosa, lo que no sería el caso; en cuanto al encaje de una persona determinada en ese motivo de cese o no renovación (falta de catolicidad), el control de los jueces estatales también ha de existir pero sólo se podría negar efecto a la decisión episcopal para casos límite en que se acredite que no había base racional alguna para considerar que esa exigencia no la cumplía el afectado (en el ejemplo mencionado, si se demuestra que la persona en cuestión no ha dejado de ser católico, aunque desde luego sin que se requiera apostasía formal).

- Si el Obispo deja de proponer a una persona por entender que otra nueva es más idónea, aunque la primera no haya dejado de serlo tampoco, debe entenderse que el control, sin embargo, se intensifica, y puede ser más denso, pues la normativa parte de que el Obispo propone a más candidatos que plazas a cubrir, por lo que la "mayor idoneidad" de uno sobre otro no ha de impedir, en principio, que por el Estado se nombre al otro, que también sería eclesialmente idóneo, al tiempo que se garantiza, sin afectar a la neutralidad estatal ni al derecho de los padres ex art. 27,3 CE, la continuidad laboral del no propuesto, que es un bien legítimo que la Administración, y en cierto modo el legislador, persiguen (al consagrar la primera la relación laboral como indefinida y establecer el primero la prórroga anual automática, aunque sujeta a no revocación eclesial).

15 Para valorar esto, es importante tener en cuenta los Criterios que la propia Confesión haya explicitado, lo que resulta conveniente que se haga con la mayor precisión posible. Véase lo que enseguida decimos respecto de la Iglesia Católica.

16 La profesión de la fe es un requisito indispensable para la docencia religiosa, pues su objeto no es la mera transmisión de conocimientos, sino también de la fe del docente: STC $38 / 2007$, FJ $100^{\circ}$. 
- Una tercera capa, relativa al conflicto del derecho de libertad religiosa (enseñanza religiosa) con los derechos fundamentales de los trabajadores en su relación de trabajo. Aquí el control se ha de hacer más denso todavía, y operar bajo el principio de proporcionalidad y concordancia práctica: cada derecho fundamental debe ceder, en ese conflicto, sólo en la medida estrictamente necesaria para salvar al otro derecho, o para evitar una afectación del otro derecho desmedida o en alguno de sus contenidos nucleares o más básicos. A ello nos hemos referido antes. En todo caso, hay que subrayar que el profesor no tiene sólo una obligación de no actuar en contra del "ideario religioso" (límite de los centros escolares privados con tal ideario frente a sus profesores) ${ }^{17}$ sino que se extiende "a la determinación de la propia capacidad para impartir la doctrina católica, entendida como conjunto de convicciones religiosas fundadas en la fe", por cuanto que el objeto de esta enseñanza lo es la transmisión "no sólo de unos determinados conocimientos sino de la fe religiosa de quien la transmite" (FJ 10. ${ }^{\circ}$, aunque habría que matizar que lo único que se evalúa con la asignatura son los conocimientos, y no en ningún caso la fe.

\section{D) CONTRATO LABORAL CON LA ADMINISTRACIÓN CON PERSONAS ELEGIDAS O DESECHADAS EN FUNCIÓN DE CRITERIOS RELIGIOSOS VERSUS NEUTRALIDAD ESTATAL EN MATERIA RELIGIOSA Y PRINCIPIO DE IGUALDAD}

En cuanto a la supuesta vinculación de la contratación laboral en el sector público a criterios religiosos, al ser requisito indispensable para la contratación la declaración eclesiástica de idoneidad respecto de cada profesor de religión, operada por la Disposición Adicional Segunda de la L.O. 1/1990, que se consideraba inconstitucional por el órgano jurisdiccional proponente al contradecir el principio de aconfesionalidad del Estado (art. 16,3 CE) así como el principio de igualdad (art. 14 con relación a los arts. 9,3 y 103,3 CE), el Tribunal Constitucional, tras descartar la aplicación del art. 23,2 CE al no ser los profesores de religión funcionarios sino contratados laborales, considera que la opción por un vínculo laboral de estos trabajadores con el Estado no era la única posible, pero que la misma no es contraria a ninguno de los preceptos constitucionales citados.

En primer lugar, en lo relativo a la igualdad, el Tribunal Constitucional recuerda que la aplicación de este principio aha de tener en cuenta el régimen jurídico sustantivo del ámbito de relaciones en que se proyecte" (STC 96/2002,

17 Cfr. SSTC 5/1981, de 13 de febrero, FJ 10. ${ }^{\circ}$; y 47/1985, de 27 de marzo, FJ $3 .^{\circ}$ (una actividad docente hostil o contraria al ideario educativo de un Centro puede ser causa legítima de despido del Profesor al que se le impute tal conducta o tal hecho singular). 
de 25 de abril, FJ 7.); que el acceso a la función pública ha de regirse por los principios de mérito y capacidad y la prohibición de diferencias entre españoles (SSTC 50/1986, de 23 de abril, FJ 4. ${ }^{\circ}$; 73/1998, de 31 de marzo, FJ 3. ${ }^{\circ}$; 138/2000, de 29 de mayo, FJ 5..$^{\circ}$ ); y que, dentro de estos límites, el legislador tiene un "amplio margen de libertad". Partiendo de ello, el Tribunal estima que en este caso los profesores de religión desempeñan una función muy específica y esto es un hecho distintivo que justifica la exigencia de la previa declaración eclesial de idoneidad de cada profesor como proporcional a los fines perseguidos por el legislador, que también tienen relevancia constitucional: garantizar «la libertad de las iglesias para la impartición de su doctrina sin injerencias del poder público".

El que la declaración de idoneidad por una iglesia sea requisito de capacidad en este caso no contraría ni la igualdad ni los principios de mérito y capacidad, ni es ajena a estos últimos, puesto que, por un lado, "se trata de contratos de trabajo que se celebran única y exclusivamente para la impartición, durante el curso escolar, de la enseñanza de la religión católicam; y de otro lado, no resultaría imaginable que las Administraciones públicas pudieran encomendar la impartición de la enseñanza religiosa en centros educativos «a personas que no sean consideradas idóneas por las respectivas autoridades religiosas para ello. Son únicamente las Iglesias, y no el Estado, las que pueden determinar el contenido de la enseñanza religiosa a impartir y los requisitos de las personas capacitadas para impartirla", siempre dentro del orden constitucional. Así pues, una vez que se acuerda con las confesiones impartir religión en los centros educativos en virtud del deber de cooperación ex art. 16,3 CE, el Estado "deberá hacerlo con los contenidos que las autoridades religiosas determinen y de entre las personas habilitadas por ellas al efecto dentro del necesario respeto a la Constitución que venimos señalando".

Además, el Acuerdo de 1979, en su artículo III, atribuye a la autoridad eclesiástica la facultad, no de "designar" a los profesores, sino de proponerlos, siendo la autoridad académica quien ha de designarlos de entre las personas "que el Ordinario diocesano proponga", lo que permite que entre esas personas "continúe rigiendo plenamente en el proceso de designación el derecho de los ciudadanos a la igualdad en el acceso al empleo público en base a criterios de mérito y capacidad. Este último argumento resulta, como ya se ha señalado antes en otro contexto, muy formalista, porque, más allá de lo que efectivamente diga el Acuerdo de Enseñanza, lo cierto es que lo habitual es que el número de propuestos por cada Obispo coincida, año tras año, con el número de plazas a cubrir, algo que nos parece que no debió pasar desapercibido al Tribunal, al menos si los derechos fundamentales que ha de proteger han de ser "reales y efectivos", y que en todo caso debería haberse mencionado en la sentencia.

El Tribunal Constitucional también destaca que la relación entre el Estado y los profesores de religión es una "categoría específica y singular", con similitudes pero también diferencias con las "empresas de tendencia", respecto 
de las que se sentó doctrina que les será aplicable, pero atendiendo igualmente a la afectación que se produzca de la libertad religiosa, así como a las dos exigencias derivadas de la dimensión objetiva de este derecho fundamental: la neutralidad religiosa de los poderes públicos, implícita en la idea de aconfesionalidad (art. 16,3 CE), y el mantenimiento de relaciones de cooperación de los poderes públicos con las diversas iglesias. Y en todo caso, el Tribunal Constitucional hace las importantes precisiones de que, por un lado, la exigencia de idoneidad conlleva no sólo, desde luego, la obligación de no actuar contra el "ideario religioso", "sino que alcanza, de manera más intensa, a la determinación de la propia capacidad para impartir la doctrina católica, entendida como conjunto de convicciones religiosas fundadas en la fe"; y por otro lado, en segundo lugar, el objeto de esta enseñanza religiosa lo es la transmisión "no sólo de unos determinados conocimientos sino de la fe religiosa de quien la transmite", lo que con toda probabilidad puede "implicar un conjunto de exigencias que desbordan las limitaciones propias de una empresa de tendencia para el trabajador, comenzando por la implícita de que quien pretenda transmitir la fe religiosa profese él mismo dicha fe" (FJ $\left.10 .^{\circ}\right)$; y en tercer lugar, la Administración no se transforma en una empresa de tendencia, algo que sería incompatible con el art. 103,1 CE (y el art. 16,3 $\mathrm{CE}$, añadiríamos nosotros), pues al contratar a los profesores de religión la Administración pública no desarrolla tendencia ni ideario ideológico alguno, "sino que ejecutan la cooperación con las Iglesias en materia de enseñanza religiosa en los términos establecidos en los acuerdos que la regulan y en las normas que la desarrollan, contratando para ello a personas que han sido previamente declaradas idóneas por las autoridades religiosas respectivas, que son las únicas que, desde el principio de aconfesionalidad del Estado, pueden valorar las exigencias de índole estrictamente religiosa de tal idoneidad".

Tampoco se aprecia, por otro lado, arbitrariedad, pues la exigencia de previa declaración de idoneidad canónica para poder ser contratados los profesores de religión responde a "una justificación objetiva y razonable coherente con los principios de aconfesionalidad y neutralidad religiosa del Estado".

Y en tercer lugar, no se aprecia vulneración de la libertad religiosa de los profesores y la prohibición de declarar sobre su propia religión (arts. 16,2 y 3 $\mathrm{CE}$ ), pues estos derechos sólo retrocederían «en la estricta medida necesaria para hacerlos compatibles con el derecho de las iglesias a la impartición de su doctrina en el marco del sistema de educación pública (arts. 16,1 y 16,3 CE) y con el derecho de los padres a la educación religiosa de sus hijos (art. 27,3 CE)", ya que "resultaría sencillamente irrazonable que la enseñanza religiosa en los centros escolares se llevase a cabo sin tomar en consideración como criterio de selección del profesorado las convicciones religiosas de las personas que libremente deciden concurrir a los puestos de trabajo correspondientes, y ello, precisamente, en garantía del propio derecho de libertad religiosa en su dimensión externa y colectiva". 


\section{EL PROBLEMA EN CONCRETO: EL RECURSO DE AMPARO RESUELTO POR LA STC 128/2007}

En la STC 128/2007, el recurrente en amparo alega que su "cese" (no renovación) como profesor de religión católica se debió a que el Obispado no le propuso para el curso 1997/98, tras varios años desempeñando tales tareas docentes, por ser sacerdote dispensado casado y por ser miembro del Movimiento Pro-celibato Opcional, alegando la vulneración del derecho a no sufrir discriminación (art. $14 \mathrm{CE}$ ), a la vida privada (art. $18 \mathrm{CE}$ ), a la libertad ideológica (art. 16 CE) y a la libertad de expresión (art. 20,1,a CE).

El Tribunal Constitucional desecha de plano una discriminación, pues el demandante había venido siendo propuesto desde 1991, cuando estaba casado desde 1985 y el Obispado lo conocía, si bien cuando se le dejó de proponer fue con ocasión de la publicidad que él dio a su condición de cura casado, al aparecer junto con su familia en un periódico de la provincia en noviembre de 1996, lo que sitúa el problema planteado en el ámbito de los derechos del art. 16,1 y 20,1,a CE. Además, añade el Tribunal Constitucional, "la neutralidad del Estado en relación con las diferentes confesiones religiosas debe operar en similares términos cuando el juicio eclesiástico de idoneidad opera positivamente en el momento de la eventual constitución de una inicial relación laboral que cuando, en sentido contrario, opera negativamente a la hora de constituir una nueva relación laboral en un curso académico posterior", tratándose la no propuesta episcopal de un juicio basado en criterios estricta y exclusivamente religiosos, sin que ese juicio sea arbitrario, discriminatorio, etc. Tampoco se aprecia vulneración del derecho a la intimidad, por cuanto que fue precisamente el demandante quien, "por su libérrima voluntad, decidió hacer públicas su situación personal y familiar, apareciendo en una información periodística fotografiado con su mujer e hijos, y su condición de miembro del Movimiento Pro-Celibato Opcional».

En cuanto a la cuestión nuclear planteada con relación a la libertad religiosa y la libertad de expresión, debe comenzar por aclararse que la decisión episcopal se produjo por cuanto que la autorización del rescripto de secularización del sacerdote (1984) autoriza al Obispo, entre otras cosas, a habilitar al sacerdote secularizado para impartir docencia de religión, entre otras condiciones, "sin peligro de escándalo". Y este se habría verificado con la publicidad consistente en un artículo publicado en el Diario "La Verdad" de Murcia, de 11 de noviembre de 1996, donde se reflejaba que el demandante de amparo participó en un intento de celebrar, junto con otros sacerdotes casados, siendo él ya secularizado, una misa en un monasterio, que les fue cerrado, permaneciendo él en el exterior junto con su familia, compuesta por su mujer y cinco hijos, y saliendo con ellos en una fotografía que acompañaba a dicho artículo, informando a los medios de comunicación y a otras personas de su situación y manifestándose en pro de un celibato opcional para los sacerdotes y una Iglesia democrática y no teocrática, marchándose posteriormente dichos sacerdotes a celebrar una eucaristía en la intimidad. Además, en dicho Diario 
expresaba su opinión contraria a la penalización del aborto y a favor del control de natalidad, y que no se podía condenar a uno por el sexo y que este es un bien divino.

A partir de aquí, comienza la ponderación de derechos fundamentales en conflicto que lleva a cabo el Tribunal Constitucional: el demandante de amparo hizo público y notorio, mediante su aparición en dicho Diario, que era un sacerdote secularizado que había contraído matrimonio civil y tenía cinco hijos y que pertenecía al Movimiento Pro-Celibato Opcional, contrario a la ortodoxia católica, y ello se integra en el concepto de "escándalo" que aplican las autoridades religiosas (ausencia de publicidad), y al ser este un juicio estrictamente religioso, el Tribunal Constitucional muestra deferencia hacia él y entra a analizarlo desde la perspectiva de los derechos fundamentales. Considera que la modulación de la libertad religiosa y de expresión del recurrente está justificada por el necesario respeto a la libertad colectiva de la Iglesia católica, el derecho de los padres ex art. 27,3 CE y el deber de neutralidad religiosa, dado que se trata de una decisión adoptada sobre criterios exclusivamente religiosos, y ello por más que el recurrente alegue que con sus opiniones "pretende defender cambios evolutivos de las normas de la confesión católica que considera que han quedado desfasadas con el paso del tiempo", pues el Tribunal Constitucional considera que no debe entrar a valorar posibles disputas intraeclesiásticas (en concreto, sobre el celibato opcional), ${ }^{18}$ ni «emitir juicio alguno sobre la adecuación y conformidad de los actos, opiniones y testimonio de la persona designada para impartir la enseñanza de determinada religión a la ortodoxia de la confesión religiosa en cuestión", sino que le basta con comprobar que sus derechos de los arts. 16,1 y 20,1, a) CE se han visto modulados sólo en la estricta medida en que lo exigían los otros derechos fundamentales en conflicto.

Desde nuestro punto de vista, lo que el Tribunal Constitucional consagra aquí es es una deferencia casi absoluta al juicio religioso. ${ }^{19}$ La conclusión al-

18 Aunque no cita jurisprudencia del TEDH, sería de aplicación la antes citada.

19 No obstante, no compartimos tampoco el criterio del Voto Particular suscrito por los Magistrados Pérez Vera y Sala, que entendemos que incurre en infracción grave del deber de neutralidad ideológica del Estado, pues pretenden reconducir el concepto de "escándalo" para la confesión a un concepto acorde con el Derecho estatal, incursionándose así en una reconstrucción de un concepto central de una confesión religiosa, como lo es, aunque eso no nos pueda gustar, el "escándalo" para la Iglesia Católica, según una tradición larguísima, presente en los Evangelios de forma expresa y ello a partir de valores e ideas ajenos a la confesión y que se le pretenden imponer. La prohibición de dar publicidad y notoriedad a la situación de cura casado del recurrente era una obligación religiosa a la que él se sometía sólo voluntariamente, sin que el Estado pueda ampararle frente a su propia confesión para defender una idea contraria a la doctrina de esta y para permitirle impartir en nombre de esta docencia religiosa (a lo que se le había autorizado sólo de forma excepcional y bajo condiciones, como exigía el Derecho canónico), pues eso sería una infracción grave de la libertad religiosa colectiva (y no meramente individual), así como del derecho de los padres a que sus hijos reciban la formación religiosa y moral católica, lo que sólo la propia Confesión puede garantizar, para que sus hijos no reciban la formación conforme a las ideas personales que tenga un sacerdote secularizado, sino precisamente las de esa confe- 
canzada por el Tribunal es profundamente respetuosa de la neutralidad estatal religiosa, pero nos parece que con una deferencia excesiva. En concreto, la decisión es intachable - aunque un tanto huérfana de una fundamentación y sistematización más convincente- en lo que se refiere a la publicidad dada a la condición de casado civilmente con cinco hijos del sacerdote secularizado, pues la autorización excepcional para la docencia, contemplada en el Derecho canónico, está condicionada a que se no haga publicidad u "ostentación" de dicha situación, lo que era conocido por el recurrente, quien optó por no cumplir con esa condición, debiendo apechar luego con las consecuencias conocidas que ello conlleva en la confesión a la que él sólo se ha querido adscribir con toda libertad, máxime cuando se le dio la "venia docendi” en esas condiciones tan excepcionales desde el punto de vista de la Confesión.

Sin embargo, la cuestión quizás se podría plantear en términos distintos en lo que se refiere a la participación, incluso pública, en el Movimiento Pro Celibato Opcional, pues es sabido que esa es una cuestión que la propia doctrina de la Iglesia Católica considera reformable o excepcionable al no ser de "Derecho divino", y la propia Iglesia se rige por la máxima de San Agustín de que «en lo fundamental, unidad; en lo accidental, libertad; y en todo mucha caridad". No obstante, lo cierto es que esa posición del demandante de amparo, que por sí sola nos parece que podría prevalecer sobre otros los derechos en conflicto, fue unida a otros posicionamientos respecto de la estructura profunda de la Iglesia (que pretendía que fuera "democrática" y no teocrática), así como a una participación activa tratando de llevar a cabo la celebración irregular de un sacramento central para los católicos, la eucaristía, de forma pública en un monasterio y por sacerdotes secularizados y casados civilmente (algo canónicamente irregular y grave). Todo ello es razonable que se juzgara por el Obispo como incompatible con la "recta doctrina" y testimonio que un profesor de religión debe profesar según el Derecho canónico y que el recurrente se había comprometido voluntariamente al entrar en esa relación laboral (y cuyo cumplimiento impide, canónicamente, al Obispo designarlo o proponerlo como profesor de religión), a lo que se suma que se le había autorizado a esa docencia sólo de manera excepcional y por decisión discrecional del Obispo, ante su condición de cura secularizado y condicionado en todo caso a que no hubiera escándalo (que para dicha Confesión es materia grave, por su efecto inductor en terceros), todo lo cual era bien conocido del recurrente (al habérsele notificado el rescripto de secularización).

sión. Se incurre en el voto particular en la tentación, siempre intensa en materia religiosa, de proyectar las ideas y convicciones propias sobre quien precisamente tiene otras creencias e ideas de tipo religioso (a veces en contraste con lo que son derechos constitucionales incluso), que es lo que precisamente protege la libertad religiosa, y quebrantando la autonomía de la confesión, y su derecho de defensa de sus convicciones: en definitiva, la tolerancia religiosa (aunque se discrepe profundamente de tales ideas); con ello, el Estado mediaría en una cuestión intraeclesial, en contra de su deber de neutralidad, y de lo que exige el Tribunal de Estrasburgo en sentencias que hemos citado más arriba. 
La no propuesta episcopal, en este contexto tomado en su conjunto, nos parece que no es susceptible de ningún reproche desde el punto de vista de los derechos fundamentales, pero sí habría que haber precisado que sí lo hubiera sido si sólo se hubiera fundamentado en la pertenencia a un Movimiento Pro Celibato Opcional (aquí sí concordamos con el voto particular a la sentencia) o incluso la defensa de esta idea fuera de las aulas, aun siendo ese posicionamiento contrario a la ortodoxia católica actual y menos todavía nos parece que podría fundamentarse la no renovación en las referencias en sí mismas del recurrente al sexo como bien divino, no una lacra, que es algo que simplemente encaja en la ortodoxia católica.

\section{REFLEXIÓN FINAL}

La doctrina sentada en la STC 38/2007, conviene destacar que por unanimidad y similar por lo demás a la de otros órganos de justicia constitucional en el ámbito comparado, ${ }^{20}$ puede resumirse en que la contratación laboral por la Administración como profesores de religión sólo de aquellas personas a las que la autoridad eclesiástica ha reconocido su idoneidad religiosa no sólo no vulnera la libertad religiosa y derecho a no declarar sobre sus propias convicciones de los profesores, sino que es garantía indispensable de la libertad religiosa de las confesiones, del derecho de los padres a que sus hijos reciban una formación religiosa y moral conforme a sus convicciones y del principio de neutralidad religiosa del Estado. Podría decirse que es manifestación de la "aconfesionalidad cooperativa" (y no, por tanto, mera aconfesionalidad) del art. 16,3 CE. Dado que la asignatura de religión, cuya impartición en las escuelas es un derecho de las iglesias a partir del art. 16,1 y 3 CE, es confesional y está orientada a la transmisión no sólo de conocimientos, sino también de la fe de quien la imparte (así dice el Tribunal Constitucional), la idoneidad eclesial desde el punto de vista religioso del docente resulta indispensable y sólo la Iglesia puede otorgar el reconocimiento de la misma, pues al Estado se lo veda el principio de neutralidad estatal en este campo, y también sería ello incompatible con el derecho de los padres a que sus hijos reciban una formación religiosa y moral acorde con sus convicciones, pues esto implica necesariamente que sea la propia confesión a la que pertenecen la que garantice debidamente la idoneidad de los docentes para que sea la doctrina de esa

20 Para Italia, véase la SCC 390/1999, de 22 de octubre, FJ 4. ${ }^{\circ}$; para Alemania, véase BVerfGE 74, 244, confirmando el carácter confesional de la asignatura de religión desde la perspectiva constitucional, sin que el Tribunal Constitucional hasta ahora haya confirmado la facultad de las autoridades religiosas de designar a los docentes, algo que se da por evidente, y que las Constituciones de algunos Länder garantizan expresamente; y ROCA, María J., "Régimen jurídico del nombramiento de los profesores de religión en las escuelas públicas alemanas", Iustel. Revista General de Derecho Canónico y Derecho Eclesiástico del Estado, núm. 14, mayo de 2007 (www.iustel.com), in toto. 
confesión, y no otra (incluso la de los legítimos "disidentes" internos), la que se transmita.

Ahora bien, el problema básico que ello plantea viene dado por los derechos del trabajador afectado al que, a instancias de la autoridad eclesial, no se le renueva su relación laboral o se le cesa, y ello no tanto con relación a sus derechos ex art. 16,1 y $2 \mathrm{CE}$, derechos que - sin admitirse nunca la arbitrariedad- de manera tácita han de ceder necesariamente al integrarse voluntariamente en esa relación laboral de docencia religiosa confesional ${ }^{21} \tan ^{-}$ especial en el sentido de no admitirse la utilización del cobijo confesional para la docencia como medio de combatir las ideas "oficiales" de la propia Confesión (algo que operaría también en los partidos políticos u otras empresas de tendencia), ${ }^{22}$ como con respecto a otros derechos fundamentales, como el de intimidad o la libertad de expresión. Aquí habrá de lograrse una "Concordancia práctica" sobre la base de ciertos criterios generales apriorísticamente formulables, y que aquí hemos tratado de concretar un poco más a partir de la doctrina del Tribunal Constitucional, pero que sobre todo remite inevitablemente a una "ponderación casuística" a la luz del principio de proporcionalidad (cuyo juego sistemático se echa un tanto de menos en la STC 38/2007), que, a su vez, permitirá ir deduciendo nuevos principios hasta crear un red más tupida que la actualmente existente, que el "leading case" de la STC 38/2007 sólo ha iniciado (y que la STC 128/2007 sólo ha comenzado a concretar). Nibil novo sub sole en materia de derechos fundamentales, por tanto.

Aparte de lo anterior, justamente en virtud de esa "concordancia práctica" sería bueno que el Estado, sin afectar por ello en absoluto a los derechos "religiosos" en juego, previera la posibilidad de incorporar o recolocar —bajo ciertas condiciones de titulación, experiencia, etc.- a los docentes "revocados" por la autoridad religiosa en otras actividades docentes en la escuela pública ajenas a lo religioso, o al menos facilitarles el acceso, incluso mediante la oposición. ${ }^{23}$ El sistema vigente en España hasta ahora, y ratificado por el Tribunal Constitucional en la STC 38/2007, ha podido dar lugar a ciertos casos ruidosos y también delicados, pero ha sido un sistema realmente poco conflictivo en términos litigiosos (varias decenas de casos judicializados sobre un total de

21 Por analogía, cfr. STC 5/1981, de 13 de febrero, FJ $10 .^{\circ}$, si bien ello se reforzaría en este caso: «La existencia de un ideario, conocida por el profesor al incorporarse libremente el centro o libremente aceptada cuando el centro se dota de tal ideario después de esa incorporación ..... Cfr. STC 128/2007, FJ 4. ${ }^{\circ}$ : "se parte de una opción personal que, como cualquier otra, lógicamente implica una autolimitación respecto de opciones diferentes".

22 Piénsese, por ejemplo, en un empleado de un partido político que es militante activo de otro partido político competidor directo del primero y despliega actividad pública a favor de ese partido; o que porta insignias del otro partido político en su trabajo, etc. Aunque en el caso de los profesores de religión, no se cumpliría tampoco el adagio de que "el que manda, paga", a diferencia de otras empresas de tendencia, pues la Administración actúa como "mediadora neutral" entre la Confesión y el profesor.

23 Para Italia, véase GONZÁLEZ-VARAS IBÁÑEZ, Alejandro, "El régimen ...", cit., pp. 32 y ss., aunque este autor se muestra contrario a lo que aquí defendemos para España. 
miles de docentes, aun habiendo numerosos profesores de religión e incluso alguna asociación de ellos, minoritaria pero significativa, opuestos a la situación actual, ahora confirmada por el Tribunal Constitucional), lo cual es en sí mismo un valor; pero no cabe duda que el resultado a que conduce en el caso de los profesores "revocados" tras muchos años de docencia sigue siendo materialmente insatisfactorio, y aunque en términos de derechos fundamentales es un sacrificio "inevitable" exigido por la coordinación de derechos en conflicto, el Estado, una vez lograda la estabilidad laboral general, debería, más allá de lo que la Constitución exige, ser sensible a esa situación y dar un cauce laboral a esas personas como el que indicábamos (que entendemos no afecta a los derechos del otro polo en conflicto), lo cual contribuiría a dulcificar el sacrificio impuesto por la resolución del conflicto de derechos fundamentales, algo que siempre puede considerarse aplicación del subprincipio de proporcionalidad en sentido estricto que entra dentro de la libertad de configuración del legislador y la Administración.

ABSTRACT. In this work, the author comments critically a recent case-law of the Constitutional Court about the cases in that the Administration doesn't renew the yearly contract to a teacher of Catholic religion in public schools because the Bishop didn't nominate him for that academic year because be failed to consider him a suitable teacher of religion, in part even on the basis of aspects related to his private life. In the Decision 38 of 2007, the Constitutional Court analyzes in abstract the compatibility with the Constitution of the Concordat which allows that "non renewall" of contract and it considers that this is in accordance with the Constitution but the Court lays down the demands that derive of the fundamental rights of the teacher and which should be kept in mind by the judges when enforcing this regulation to the concrete cases. In the Decision 128/2007, the Courth itself reviews a first concrete case of application of this doctrine. The Court gives great deference to the religious opinion of the Bishop when the "non renewal" is based on religious motivations in order to respect the collective freedom of religion. 